\title{
Synthesis of Platinum Nanocrystals within Iodine Ions Mediated
}

\author{
Jiamao Li, ${ }^{1}$ Jingwei Hou, ${ }^{2}$ Yu Gong, ${ }^{2}$ Chengjian Xiao, ${ }^{2}$ Lei Yue, ${ }^{2}$ Linjie Zhao, ${ }^{2}$ Huan Ma, ${ }^{2}$ \\ Heyi Wang, ${ }^{2}$ Shuming Peng $\mathbb{D}^{2},{ }^{2}$ Chao Chen $\mathbb{D}^{2},{ }^{2}$ and Hongli Chen $\mathbb{D}^{1}$ \\ ${ }^{1}$ School of Physical Sciences, University of Science and Technology of China, Hefei, Anhui 230027, China \\ ${ }^{2}$ Institute of Nuclear Physics and Chemistry, China Academy of Engineering Physics, Mianyang, Sichuan 621900, China
}

Correspondence should be addressed to Chao Chen; zwy_chenchao@126.com and Hongli Chen; zkd_chl@126.com

Received 12 February 2018; Accepted 22 April 2018; Published 26 August 2018

Academic Editor: Vincenzo Baglio

Copyright ( 2018 Jiamao Li et al. This is an open access article distributed under the Creative Commons Attribution License, which permits unrestricted use, distribution, and reproduction in any medium, provided the original work is properly cited.

\begin{abstract}
A liquid-phase reducing method of synthesizing Pt nanocrystals was demonstrated, and dendrite-, cube-, and cuboctahedronshaped Pt nanocrystals (NCs) with well-defined monomorphic were successfully synthesized through iodine ions mediated with the CTAB agent. When the KI concentration was increased to thirty times of $\mathrm{K}_{2} \mathrm{PtCl}_{4}$ at the nucleation stage, the highquality Pt nanodendrites could be obtained. However, no matter how many KI were added at the growth age, only cube- and cuboctahedron-shaped Pt nanocrystals formed. The results of high-resolution TEM, EDX, and XRD indicated that the size and shape of Pt NCs could be turned by changing the concentration and time of KI. In the nucleation stage, it might be due to that some iodine ions adsorb on the surfaces of Pt NCs, which probably cause the rapid growth process resulting in the formation of $\mathrm{Pt}$ nanodendrites. In the growth stage, although high concentrations of $\mathrm{I}^{-}$ions could contribute to the shape control and generate bigger particles of Pt NCs, small Pt particles do not grow into dendrites. The insight into the role of $\mathrm{I}^{-}$ions in synthesis of Pt NCs reported here provided a viewpoint for clearly understanding the formation mechanism of anisotropic platinum nanostructures.
\end{abstract}

\section{Introduction}

Recently, the remarkable progress of nanotechnology has attracted great attention [1-6], mainly due to the ability to finely control the shape and size of metal nanocrystals (NCs) in order to manipulate their electronic [7, 8], optical [9], and catalytic properties [10, 11]. Among metals, Pt has received remarkable interest primarily because it plays a crucial role in various catalytic reactions [12-14], such as hydrogenation production [15] and fuel oxidation in fuel cell technology [16-18]. The main drawback in the use of $\mathrm{Pt}$ is its scarceness, directly implying high costs. It is therefore essential to reduce the amount of Pt used in any application, in order to lower the overall cost. Some reports demonstrated that the catalytic performance of Pt NCs strongly depends on their size, shape, composition, and surface structure [12, 19]; for these reasons, Pt NCs have gained consideration in the development of high-activity Pt-based catalysts characterized by low amounts of Pt. So far, various approaches (physical, chemical, and biological methods) have been devoted to controlling the structure of Pt materials [20].

Among the viable Pt NC synthesis methods, the solutionphase chemical reaction process is the more appropriate and cost-effective way to obtain Pt NCs with well-defined shapes $[21,22]$; the most common is the polyol process $[23,24]$. This method consists essentially in the reduction of a metal salt by a polyol and always occurs at elevated temperatures [25]. In this case, the polymeric stabilizer polyvinylpyrrolidone $(\mathrm{PVP})$ is used as an organic protective and reducing agent to synthesize shape- and size-controlled Pt NCs $[25,26]$. Although PVP as a surface-regulating polymer has been widely used in various synthetic paths for Pt NCs, it still has some drawbacks, mainly because PVP tends to strongly interact with the Pt surface [27]. This interferes with the catalytic properties, because surface features significantly contribute to catalytic reactions. If some agents are absorbed on the surface of the catalytic particle, the probability of contact between the reactants is suppressed, causing the catalytic performance of metal NCs to diminish [28]. 
Compared with the carbonyl group, alkylammonium ions $\left(\mathrm{CTA}^{+}\right)$have much weaker interactions with the Pt surface, because the tetradecyltrimethylammonium bromide(TTAB-) capped Pt NCs are characterized by higher catalytic activity than PVP-capped Pt NCs are $[12,28]$. Because cetyltrimethylammonium bromide (CTAB) is structurally related to TTAB, CTAB also can be considered to be an effective surface-stabilizing agent to regulate the shape of Pt NCs. Ullah et al. reported that 3D dendritic Pt nanoclusters could be synthesized at a $\mathrm{pH}$ of $\sim 1.7$ using $\mathrm{CTAB}$, and the Pt nanodendrites showed excellent electrocatalytic activity for the reduction of $\mathrm{O}_{2}$ [29].

In addition to polymeric stabilizers and surfactants, ionic impurities $\left(\mathrm{Ag}^{+}[23], \mathrm{Fe}^{2+}[30]\right.$ or $\mathrm{Fe}^{3+}[30,31], \mathrm{NO}_{3}{ }^{-}[32]$, and $\mathrm{Br}^{-}$[33]) also contribute to the shape-controlled process in Pt NCs, implying that ionic impurities can be efficiently added to the solvent in order to realize the morphology control of Pt materials. As an example, Chen et al. [30] reported the synthesis of long single-crystalline platinum nanorods by adding $\mathrm{Fe}^{2+}$ or $\mathrm{Fe}^{3+}$ to the solvent in the polyol process. They found that $\mathrm{Fe}^{2+}$ or $\mathrm{Fe}^{3+}$ greatly reduced the reaction rate; moreover, the ionic impurities served as nucleation sites to induce the aggregation of $\mathrm{Pt} \mathrm{NCs}$ into larger structures. Herricks and coworkers [32] reported the effect of $\mathrm{NO}_{3}{ }^{-}$on the growth of $\mathrm{Pt} \mathrm{NCs}$. They argued that $\mathrm{NO}_{2}{ }^{-}$could be formed by the reduction of $\mathrm{NO}_{3}{ }^{-}$in the early stages of the polyol process, slowing down the overall reduction rate of the polyol reaction, because they formed stable complexes with $\mathrm{Pt}^{2+}$ and $\mathrm{Pt}^{4+}$. The slower reduction rate causes an overgrowth of the corners of the tetrahedron and octahedron. The effect of $\mathrm{Br}^{-}$has been widely investigated in many Pt NC synthetic processes. It has been reported that by adding aqueous $\mathrm{NaBH}_{4}$ to a solution of $\mathrm{K}_{2} \mathrm{PtCl}_{4}, \mathrm{KBr}$, and $\mathrm{Na}_{2} \mathrm{H}_{2} \mathrm{P}_{2} \mathrm{O}_{7}$ with slow dripping speed, $\mathrm{Pt}$ concave nanocubes enclosed by high-index facets can be obtained [33]. In this growth process, the selective overgrowth of $\mathrm{Pt}$ seeds at the edges and corners and the capping activity of $\mathrm{Br}^{-}$ions block the growth of the $<100>$ axis. In addition to $\mathrm{Br}^{-}$, effects of $\mathrm{I}^{-}$ ions on the growth of $\mathrm{Pt} \mathrm{NCs}$ have also been investigated. For example, Yin et al. [25] reported the synthesis of monomorphic single-crystalline Pt nanoflowers by adding $\mathrm{I}^{-}$ions to the reaction solution. Moreover, the results obtained by Miyake and Miyabayashi [34] showed that time at which $\mathrm{I}^{-}$ions are added plays a key role in tuning the shape and size of $\mathrm{Pt}$ NCs. More recently, $\mathrm{I}^{-}$ions have gained great attention for their capability to directly shape Pt NCs, since they bind more strongly to $\mathrm{Pt}$ than any other halide ion, which results in a strongly decreased reduction rate of $\mathrm{Pt}$ atoms bound to $\mathrm{I}^{-}$ions [19].

Although the effect of $\mathrm{I}^{-}$ions has been reported in many polyol processes, to the best of our knowledge, there are only few results concerning the extraordinary role of $\mathrm{I}^{-}$ions in the synthesis of Pt NCs with the CTAB capping agent $[29,35]$. Most importantly, due to that dendrite-, cube-, and cuboctahedron-shaped Pt have exhibited great catalytic performance in various reactions $[11,29]$, therefore it is very meaningful to find an easy way to form them. Herein, we report a synthetic method in which CTAB is used as surface-stabilizing agent to prepare monodisperse Pt NCs.
We propose a facile and simple synthesis of $\mathrm{Pt}$ nanodendrites, octahedra, and cubes, achieved by only changing the timing and the amount of $\mathrm{I}^{-}$ions. Moreover, the effect of $\mathrm{I}^{-}$ ions on the shape of Pt NCs synthesized using the CTAB agent has been reported.

\section{Experimental Procedures}

2.1. Chemicals and Materials. Potassium tetrachloroplatinate(II) $\left(\mathrm{K}_{2} \mathrm{PtCl}_{4}, 99.9 \%\right)$, cetyltrimethylammonium bromide (CTAB, 99\%), potassium iodide (KI, 99\%), and sodium borohydride $\left(\mathrm{NaBH}_{4}, 98 \%\right)$ were purchased from Shanghai Aladdin Bio-Chem Technology Co., Ltd. All materials were used as received. Deionized water with a resistivity of 18.2 $\mathrm{M} \Omega \cdot \mathrm{cm}$ was used for all experiments as obtained from a Milli-Q system.

2.2. Synthesis of Pt NCs. Four synthetic routes of Pt NCs were exploited for all experiments. In route $\mathrm{I}, 0.05 \mathrm{mmol}$ of $\mathrm{K}_{2} \mathrm{PtCl}_{4}$ and $5 \mathrm{mmol}$ of CTAB were directly added to $20 \mathrm{~mL}$ of deionized water at room temperature. The mixture was stirred, heated, and refluxed at $50^{\circ} \mathrm{C}$ until the solution became clear. After that, $0.5 \mathrm{~mL}$ of a $3 \mathrm{M}$ aqueous solution of $\mathrm{NaBH}_{4}$ at $0^{\circ} \mathrm{C}$ was added. Then, $\mathrm{H}_{2}$ flow in wild passed through the three-necked flask. The $\mathrm{H}_{2}$ flow and temperature were kept at the same state for $6 \mathrm{~h}$. In addition, no other solution was added into the mixture during the whole process of route I. Synthetic routes (II, III, and IV) began with the preparation of $0.75 \mathrm{M} \mathrm{CTAB}\left(\mathrm{C}_{1}\right)$ added with a certain amount of KI. In particular, we prepared three different solutions characterized by the following mole ratios of KI and CTAB: $1: 6$ $\left(M_{1}\right), 1: 2\left(M_{2}\right)$, and 1:1 $\left(M_{3}\right)$. Solutions $C_{1}, M_{1}, M_{2}$, and $\mathrm{M}_{3}$ were maintained at $50^{\circ} \mathrm{C}$ in a water bath. Routes II, III, and IV were somewhat similar to route I, in that all of them had the same synthetic method in the early stage, except that a process of hot injection was employed at different times. "Hot injection" $[3,36]$ is the injection of hot reagents into an already hot solution. In route II, after the addition of ice-cold aqueous solution $\mathrm{NaBH}_{4}$ for $30 \mathrm{~min}, 2 \mathrm{~mL}$ each of $\mathrm{C}_{1}, \mathrm{M}_{1}, \mathrm{M}_{2}$, and $\mathrm{M}_{3}$ was injected into the flask. In route III, $2 \mathrm{~mL}$ each of $\mathrm{C}_{1}, \mathrm{M}_{1}, \mathrm{M}_{2}$, and $\mathrm{M}_{3}$ was added after $\mathrm{NaBH}_{4}$ was added for $120 \mathrm{~min}$. In addition, when $\mathrm{NaBH}_{4}$ was added for $240 \mathrm{~min}, 2 \mathrm{~mL}$ each of $\mathrm{C}_{1}, \mathrm{M}_{1}, \mathrm{M}_{2}$, and $\mathrm{M}_{3}$ was added into the flask (route IV). For all routes, the $\mathrm{H}_{2}$ flow and temperature of $50^{\circ} \mathrm{C}$ were maintained for $6 \mathrm{~h}$. The products of routes I, II, III, and IV were separated and centrifuged twice at $12,000 \mathrm{rpm}$ for $10 \mathrm{~min}$. The precipitates were collected and redispersed in deionized water.

2.3. Material Characterization. Transmission electron microscopy (TEM), high-resolution transmission electron microscopy (HRTEM), and energy-dispersive X-ray spectroscopy (EDX) analyses were performed using a Carl Zeiss-Libra 200 microscope operated at $200 \mathrm{kV}$ by drop casting the nanoparticle dispersions on carbon-coated copper grids and drying under ambient conditions. Powder X-ray diffraction (XRD) patterns were recorded on an X-ray instrument (X'Pert PRO) using CuK $\alpha(\lambda=0.15406 \mathrm{~nm})$ radiation at $40 \mathrm{kV}$ and $40 \mathrm{~mA}$, in a continuous scan mode. 


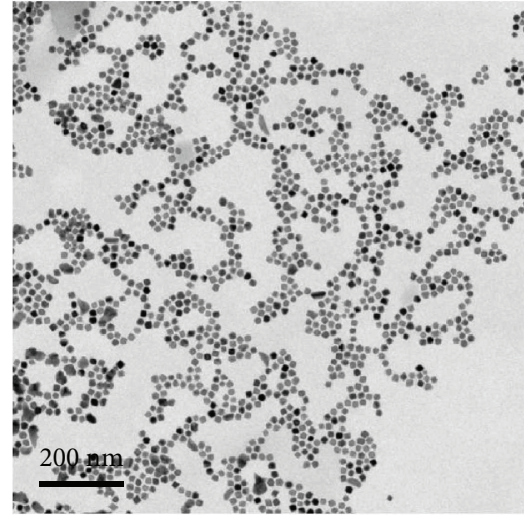

(a)

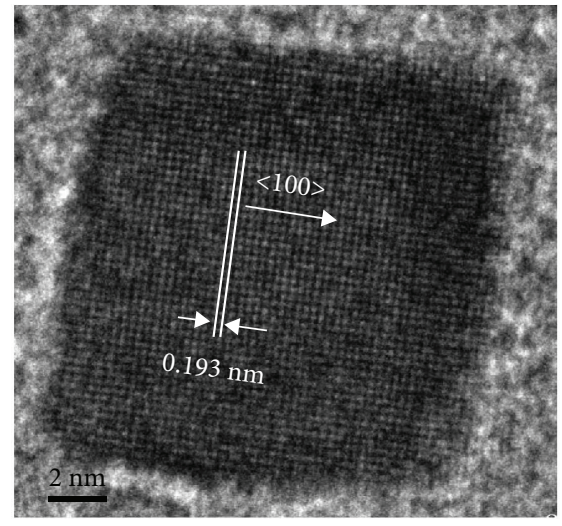

(c)

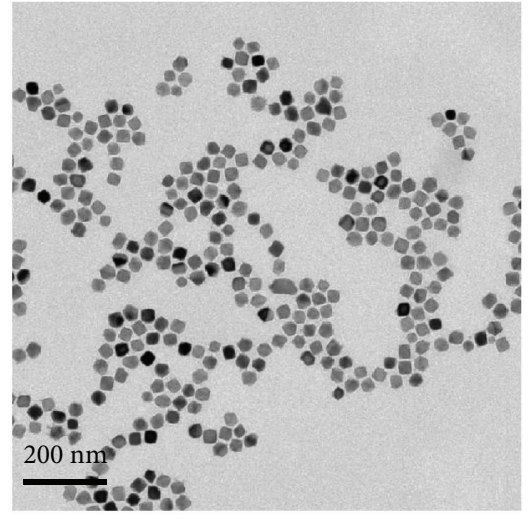

(b)

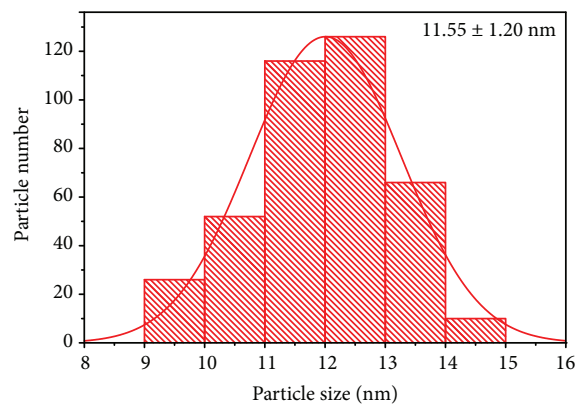

(d)

Figure 1: TEM images of monomorphic Pt cubes (a) and (b) are TEM images of cubic Pt NCs, (c) HRTEM images of a single cubic Pt NC, and (d) size distribution of CTAB-stabilized cubic Pt NCs.

\section{Results and Discussion}

3.1. Structural Characterization of Pt NCs. The addition of platinum salt to a mixture of water and CTAB caused the formation of a composite colloid containing both $\mathrm{Pt}^{2+}$ and $\mathrm{CTA}^{+}$, which exhibited the color yellow. With the help of mild heating $\left(50^{\circ} \mathrm{C}\right)$, the reduction process of $\mathrm{Pt}^{2+}$ occurred very fast in the presence of a strong reducing agent $\left(\mathrm{NaBH}_{4}\right)$. The color of solution immediately changed from yellow to dark brown, exhibiting the fast reduction of $\mathrm{Pt}^{2+}$ to $\mathrm{Pt}^{0}$ species. Figure 1 shows TEM images of the Pt cubic NCs [11] prepared by mixing $0.05 \mathrm{mmol}$ of $\mathrm{K}_{2} \mathrm{PtCl}_{4}, 5 \mathrm{mmol}$ of $\mathrm{CTAB}$, and $1.5 \mathrm{mmol}$ of $\mathrm{NaBH}_{4}$ in deionized water at $50^{\circ} \mathrm{C}$. Figures 1(a) and 1(b) shows low-magnification TEM images which clearly show that Pt NCs are well-defined and monomorphic ( $86 \%$ cubic, $12 \%$ tetrahedral, $2 \%$ irregular particles), with an average size of $11.55 \pm 1.20 \mathrm{~nm}$ (Figure $1(\mathrm{~d})$ ). For the Pt cube (Figure 1(c)), the fringes exhibit a period of $0.193 \mathrm{~nm}$, which is consistent with the (200) lattice spacing of facecentered cubic (fcc) Pt. Ahmadi et al. [21] and Petroski et al. [37] had reported a mechanism that most of the catalytically active $\{111\}$ surface of Pt had been affected by a competition between the polymer capping and $\mathrm{H}_{2}$ reduction of the $\mathrm{Pt}^{2+}$ complex. In this process, we speculated that the rapid reduction of $\mathrm{Pt}^{2+}$ on the $\{111\}$ surface by $\mathrm{NaBH}_{4}$ might lead to its disappearance and the formation of $\{100\}$ faces due to the deposition of Pt atoms on it. Therefore, the Pt cubic NCs are synthesized by this method.

Figure 2 shows TEM images of cuboctahedral Pt NCs [11, 23], which were prepared by route III, in which $M_{3}$ was added into the mixture at $50^{\circ} \mathrm{C}, 120 \mathrm{~min}$ after the synthetic reaction started. Figure 2(a) shows a low-magnification TEM image of cuboctahedral Pt NCs, vertex to vertex, in which we found $78 \%$ cuboctahedra, $16 \%$ cubic, and $6 \%$ irregular-shaped Pt NCs. Figure 2(b) is a representative HRTEM image of a single cuboctahedral Pt NC. It clearly exhibits a separation angle of about $70^{\circ}$ and a lattice fringe image of $\{111\}$ planes with the interplanar distance of $0.226 \mathrm{~nm}$. Figure $2(\mathrm{c})$ shows the particle size distribution of cuboctahedral Pt NCs, their average size being about $14.68 \mathrm{~nm}$. The significantly greater average size of cuboctahedral Pt NCs as compared to cubic Pt NCs (Figure 2(c) compared to Figure $1(\mathrm{~d})$ ) is supposed to be a direct consequence of the effect of $\mathrm{I}^{-}$ions on the growth of Pt NCs.

Figures 3(a) and 3(b) show TEM images of Pt nanodendrites $[38,39]$ prepared by route II, in which the $M_{3}$ solution at $50^{\circ} \mathrm{C}$ was added to the mixed solution, $30 \mathrm{~min}$ after the synthetic reaction started. Figure 3(a) shows a low-magnification TEM image, exhibiting that all Pt NCs have a dendrite-like structure with multibranched subunits. Figure 3(b) shows the HRTEM image of a single Pt nanodendrite, from which further insights into the structure of these 


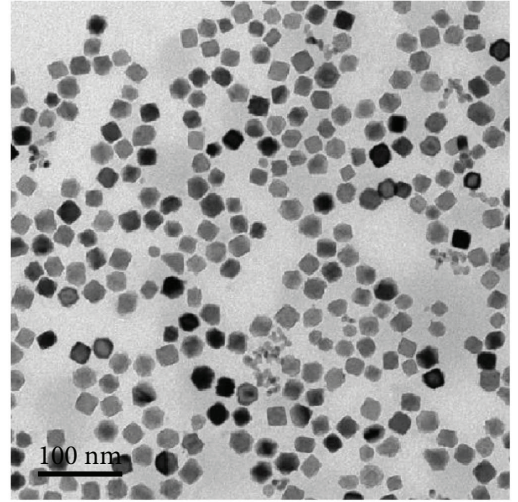

(a)

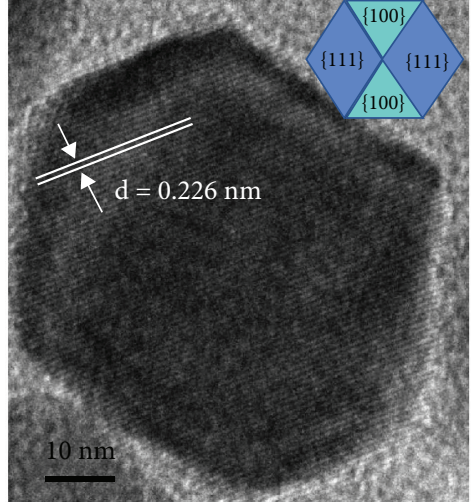

(b)

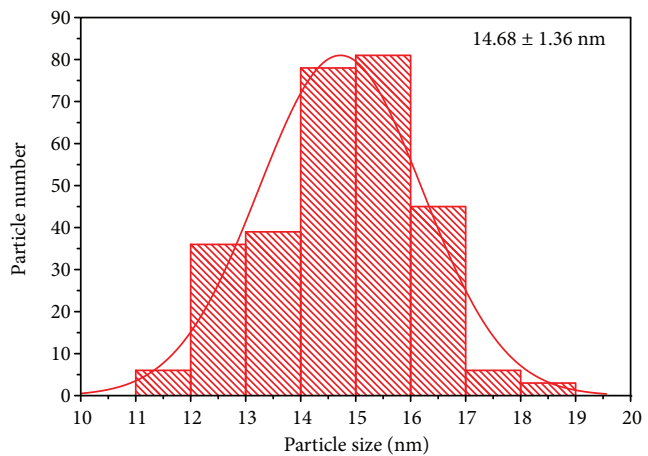

(c)

FIgUre 2: TEM images of cuboctahedral Pt NCs. (a) Low-magnification TEM image of cuboctahedral Pt NCs, (b) HRTEM images of a single cuboctahedral Pt NC, and (c) size distribution of CTAB-stabilized cuboctahedral Pt NCs.

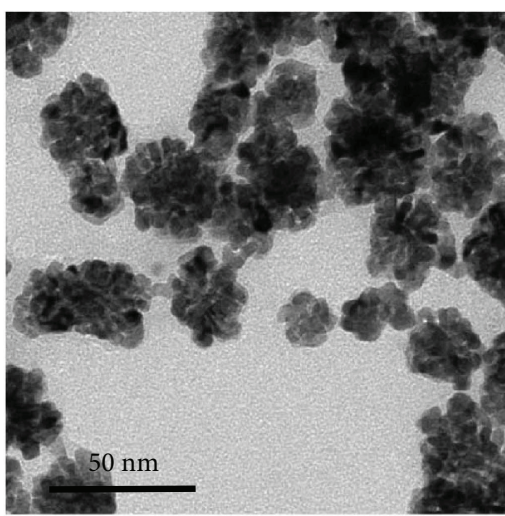

(a)

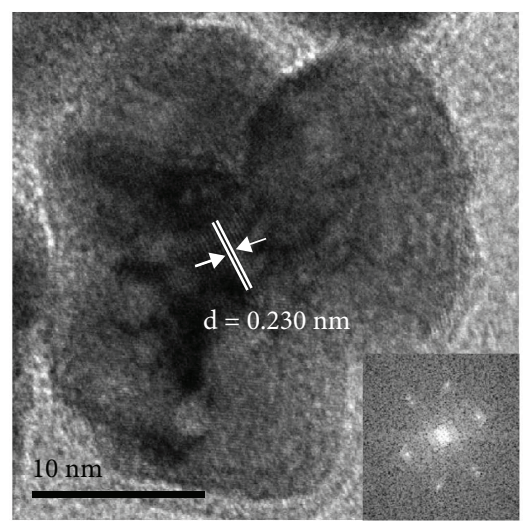

(b)

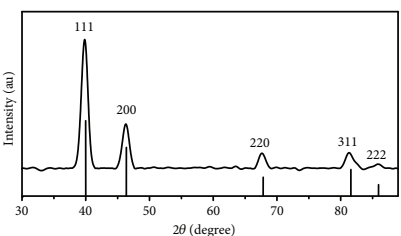

(c)

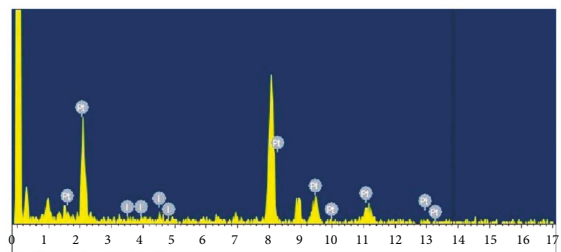

(d)

FIgURe 3: Structural characterizations of Pt nanodendrites. (a) Low-magnification TEM image, (b) HRTEM image of a single Pt nanodendrite (inset image shows the Fourier transform (FT) pattern), (c) XRD patterns, and (d) EDX spectrum.

nanoparticles can be inferred. Inside the individual $\mathrm{Pt}$ nanodendrites, many petals can be observed and are about $10 \mathrm{~nm}$ in width. The petals cause some interspaces, which may confirm that the Pt nanodendrites have a porous nanostructure. The observed lattice fringes in Figure 3(b) correspond to the $\{111\}$ plane of Pt based on interplanar spacing measurements $(0.230 \mathrm{~nm})$. The data of HRTEM and the FT pattern (Figure 3(b), inset) for individual Pt nanodendrites indicate the single-crystalline nature of the highly branched Pt nanoarchitecture.

Figure 3(c) shows the XRD spectra of Pt nanodendrites. The results of the XRD analysis indicate that the Pt nanodendrites are fcc cubic crystals, and its five peaks match the Pt standard pattern peaks of (111), (200), (220), (311), and (222). Figure 3(d) exhibits the results of EDX investigation of Pt nanodendrites, confirming that a large amount of elemental Pt is present in the nanodendrites. Moreover, peculiar signals characteristic of $\mathrm{I}^{-}$ions were detected, as shown in Figure 3(d). Although the final products from route II were washed many times with deionized water and ethanol, a small amount of $\mathrm{I}^{-}$ions was found, suggesting that some $\mathrm{I}^{-}$ ions may have absorbed to the surfaces of the Pt nanodendrites. The above results suggest that the addition of $\mathrm{I}^{-}$ions leads to formation of different shapes of Pt NCs; the effect of $\mathrm{I}^{-}$ions will be discussed in detail below.

3.2. Effects of $\Gamma$ Ions on the Nucleation Stage. So far, few studies have explained the effect of $\mathrm{I}^{-}$ions on the growth of $\mathrm{Pt}$ $\mathrm{NCs}$, in which $\mathrm{CTAB}$ is used as a surface-stabilizing agent. The addition of $\mathrm{I}^{-}$ions into a mixed solution (CTAB) causes the solution to become viscous (Figures 4(c) and 4(d)). The fresh mixture $\left(0.05 \mathrm{mmol} \mathrm{K}_{2} \mathrm{PtCl}_{4}\right.$ and $\left.5 \mathrm{mmol} \mathrm{CTAB}\right)$ was heated at $50^{\circ} \mathrm{C}$ for about $5 \mathrm{~min}$ until the solution became clear [35], as shown in Figure 4(a). However, if $1.5 \mathrm{mmol}$ of $\mathrm{KI}$ is injected into the mixture, the solution soon turns to a yellow viscous solution. The addition of an ice-cold aqueous solution of $\mathrm{NaBH}_{4}$ causes the initial mixture to become darker, but still clear, as shown in Figure 4(b). When $1.5 \mathrm{mmol}$ KI solution is added to the latter, the clear solution becomes viscous (Figure 4(c)). At this point, the viscous mixture may limit the mass transfer of Pt sources, therefore interfering with the synthesis of shape-controlled Pt NCs. Figure 4(e) 


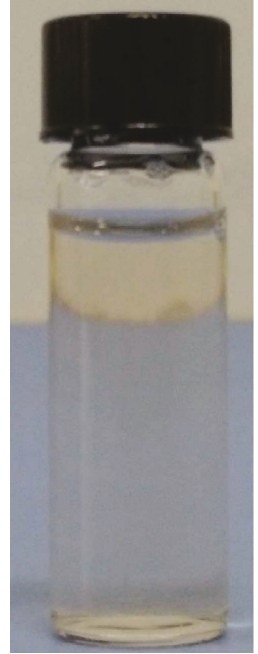

(a)

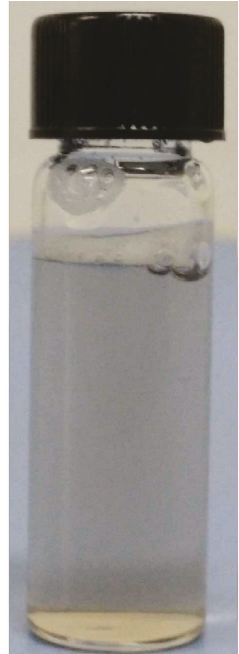

(b)

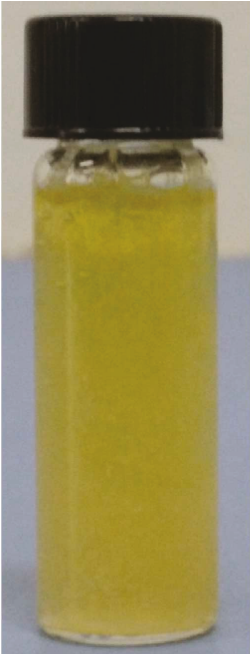

(c)

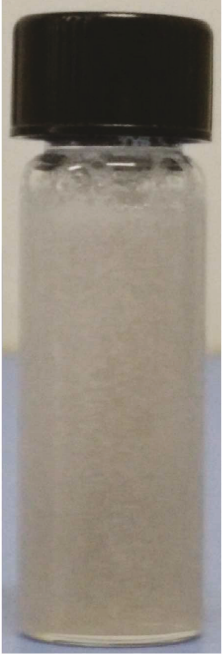

(d)

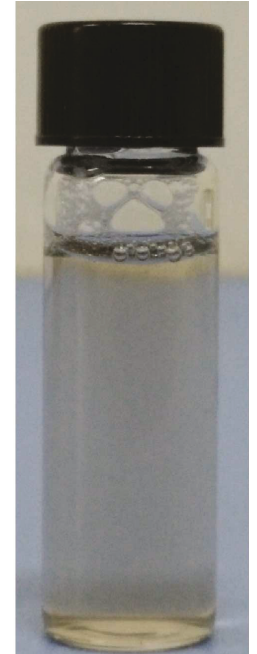

(e)

FIgure 4: Reaction solutions of $\mathrm{K}_{2} \mathrm{PtCl}_{4}$, CTAB, and $\mathrm{KI}$ used in the synthesis of Pt NCs. (a) $\mathrm{K}_{2} \mathrm{PtCl}_{4}$ and CTAB mixture, (b) ice-cold NaBH 4 solution added to (a), (c) KI solution added to (a), (d) KI solution added to (b), and (e) $\mathrm{M}_{3}$ solution added to (b).

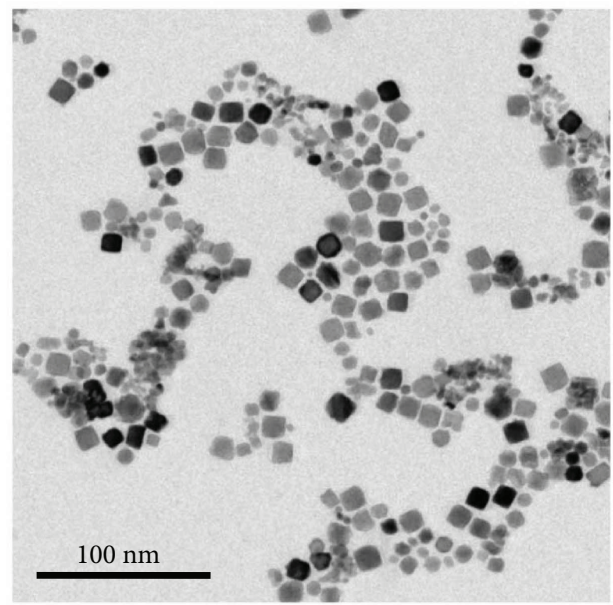

(a)

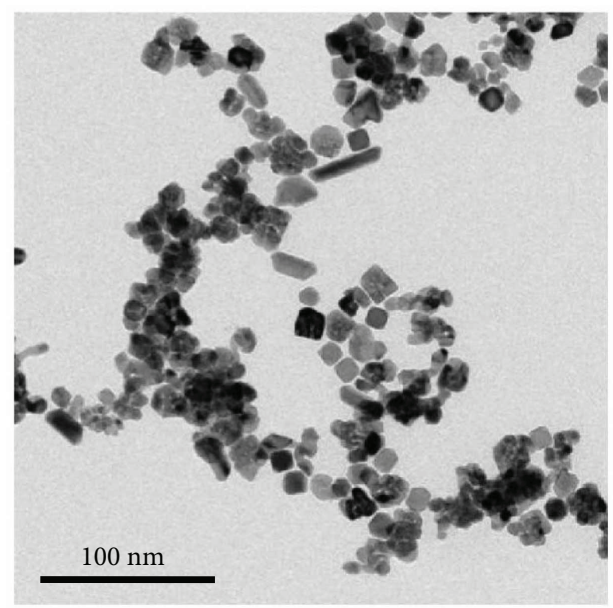

(c)

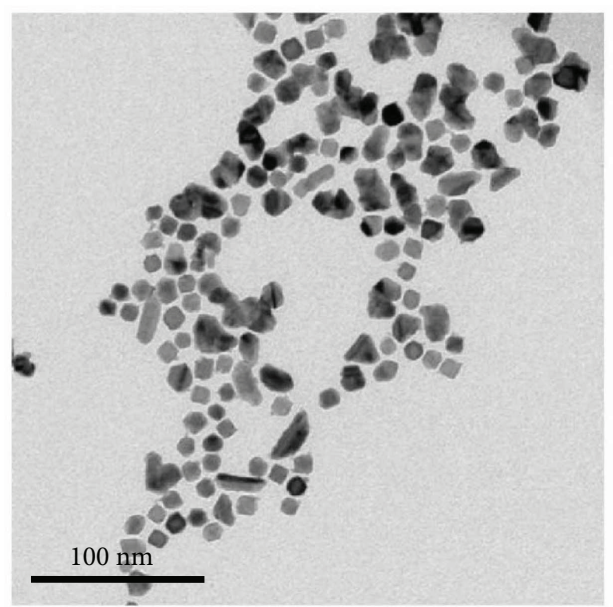

(b)

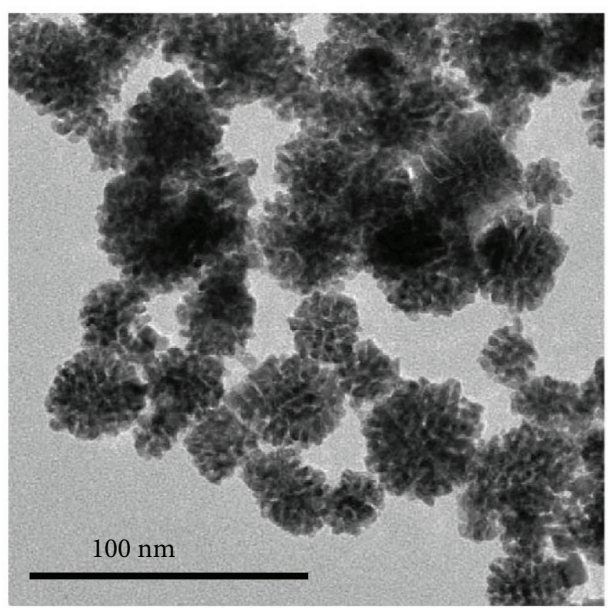

(d)

Figure 5: TEM images of Pt NCs synthesized by route II with different KI concentrations: (a) $0 \mathrm{mmol}$, (b) $0.25 \mathrm{mmol}$, (c) $0.75 \mathrm{mmol}$, and (d) $1.5 \mathrm{mmol}$. 


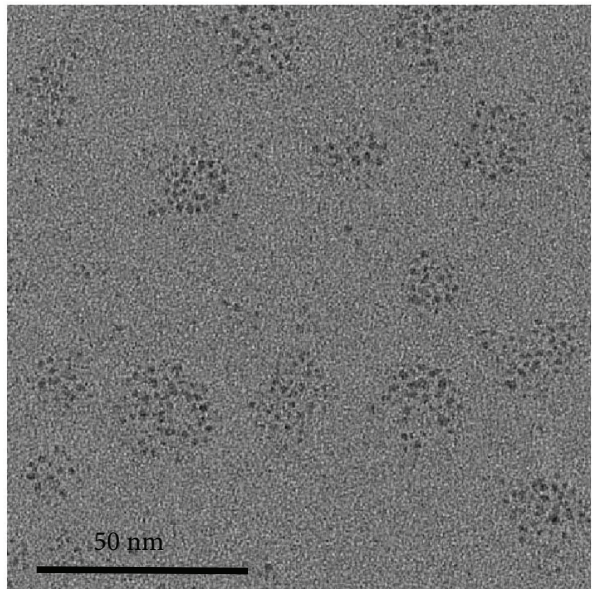

(a)

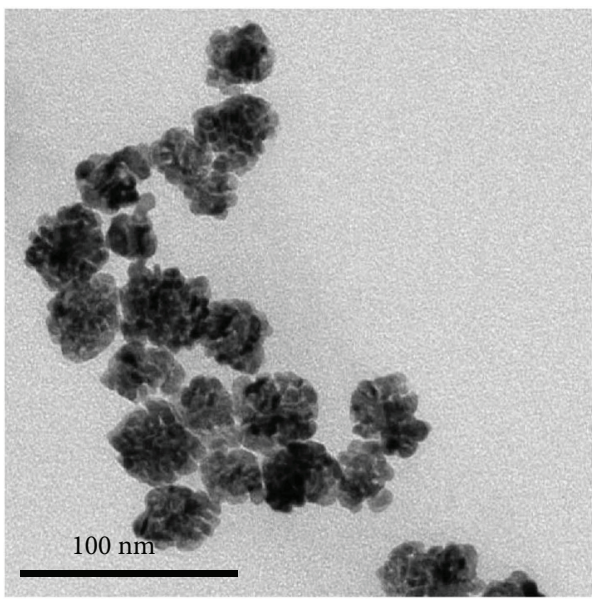

(c)

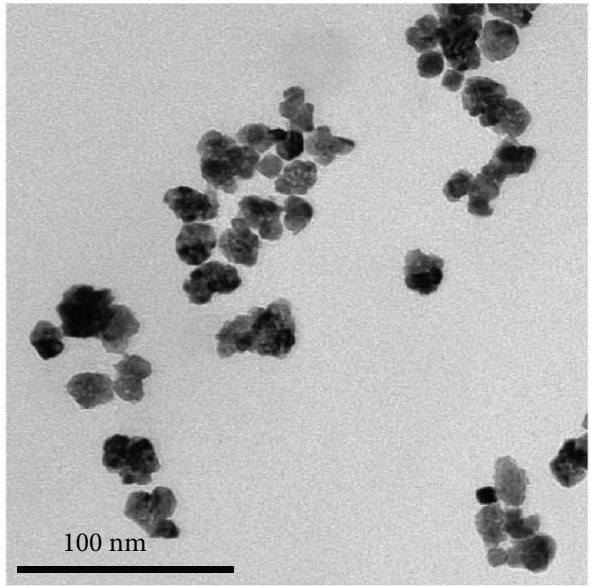

(b)

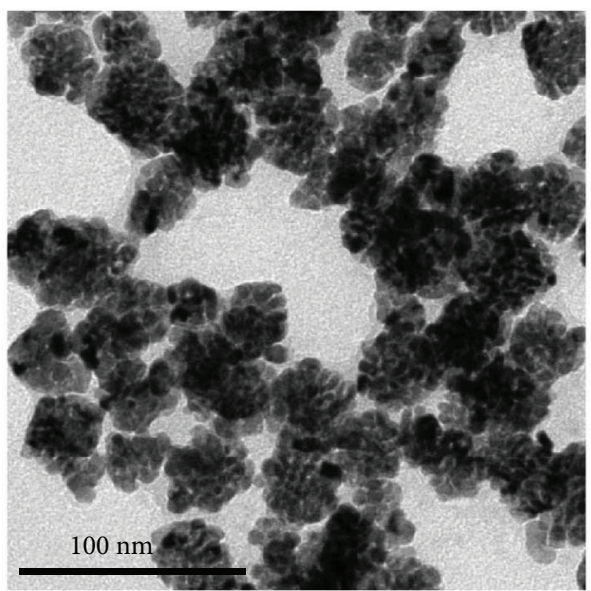

(d)

Figure 6: TEM images of Pt NCs collected at different reaction stages using route IV: (a) $30 \mathrm{~min}$, (b) $60 \mathrm{~min}$, (c) $240 \mathrm{~min}$, and (d) $360 \mathrm{~min}$

shows the initial mixture added with the $\mathrm{M}_{3}$ solution; in this case, the solution was still clear, suggesting that routes II, III, and IV might solve the problem of mass transfer.

Figure 5 shows TEM images of Pt NCs synthesized by route II, but with different $\mathrm{KI}$ concentrations. The results clearly indicate a significant variance of the morphology of Pt NCs as the KI concentration is gradually increased. Without any $\mathrm{KI}$ in the solution $\left(2 \mathrm{~mL}, \mathrm{c}_{1}\right)$, most of the Pt structures are cubic NCs; however, since the morphology of Pt NCs is the same, the injection of additional CTAB caused the growth of many smaller cubic Pt NCs, as can be seen in Figure 5(a). At a very low concentration of KI (Pt: I=1:5), rod-, sphere-, and triangle-shaped NCs are observed (Figure 5(b)). As the concentration of KI is increased (Pt: $\mathrm{I}=1: 15)$, the particles of Pt NCs grow bigger. Moreover, in this case, some particles tend to adhere to each other, and small Pt clusters appear (Figure 5(c)). At a Pt: I ratio of $1: 30$, sphere- and rod- structures disappear, and a large amount of Pt nanodendrites are observed (Figure 5(d)).

The formation process of Pt nanodendrites was investigated by a time sequential evolution experiment. The growth products of Pt NCs were collected at different stages and characterized by TEM. Thirty minutes after the addition of ice-cold $\mathrm{NaBH}_{4}$ to the mixtures, a large amount of small Pt NCs are formed, characterized by irregular shapes and a diameter of about $2-3 \mathrm{~nm}$, as shown in Figure 6(a). Thirty minutes after the addition of $\mathrm{M}_{3}$, small Pt nanodendrites were observed, as shown in Figure 6(b). Upon increasing the reaction time, the particles of $\mathrm{Pt}$ nanodendrites grew into larger and denser nanoparticles, as shown in Figures 6(c) and 6(d).

The aforementioned results suggest that $\mathrm{I}^{-}$ions play an important role in the growth process of Pt nanodendrites. However, this growth process may be different with respect to the formation of platinum nanoflowers using the KImediated polyol process [25]. The formation of Pt nanodendrites might be from the rapid growth mechanism [39-41], in which several small Pt NCs were first formed as seeds and then rapidly grew into dendrites by the induced action of $\mathrm{I}^{-}$ions. The growth mechanism of $\mathrm{Pt}$ nanodendrites may be described like this. First, $\mathrm{Pt}^{2+}$ ions are adsorbed onto $\mathrm{CTAB}$, then the complex ions are reduced by $\mathrm{BH}_{4}{ }^{-}$ions and form $\mathrm{CTAB}$-encapsulated $\mathrm{Pt}^{0}$. Due to the strong reduction capacity of $\mathrm{NaBH}_{4}$, the CTAB-encapsulated $\mathrm{Pt}^{0}$ immediately increases to a high concentration. Moreover, a large 


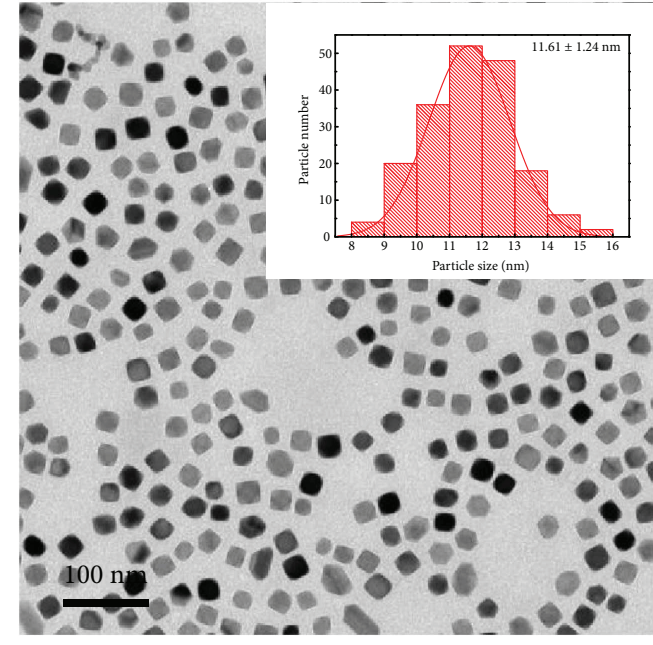

(a)

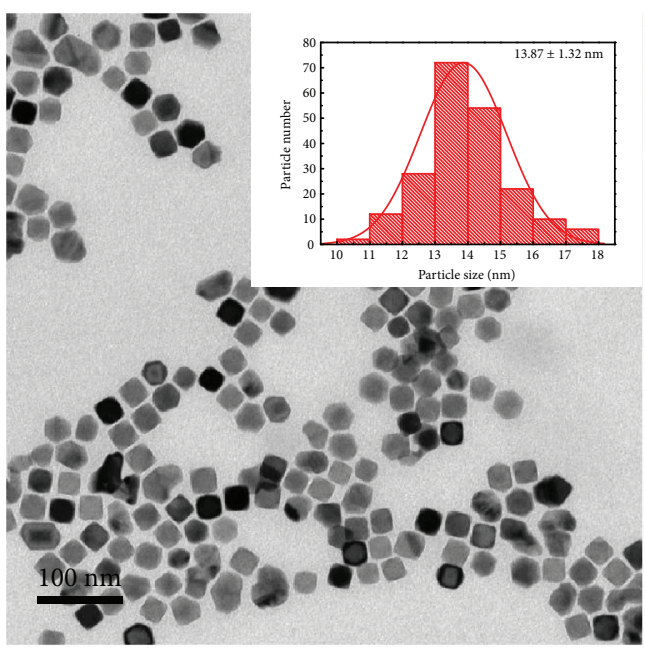

(c)

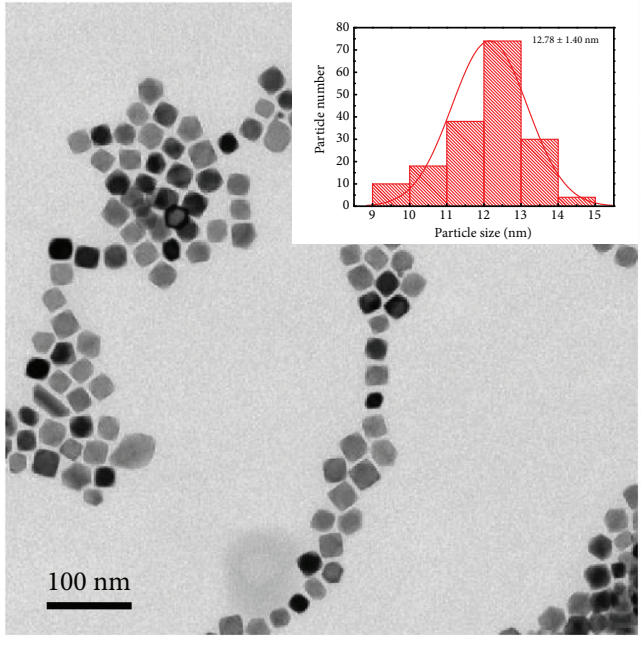

(b)

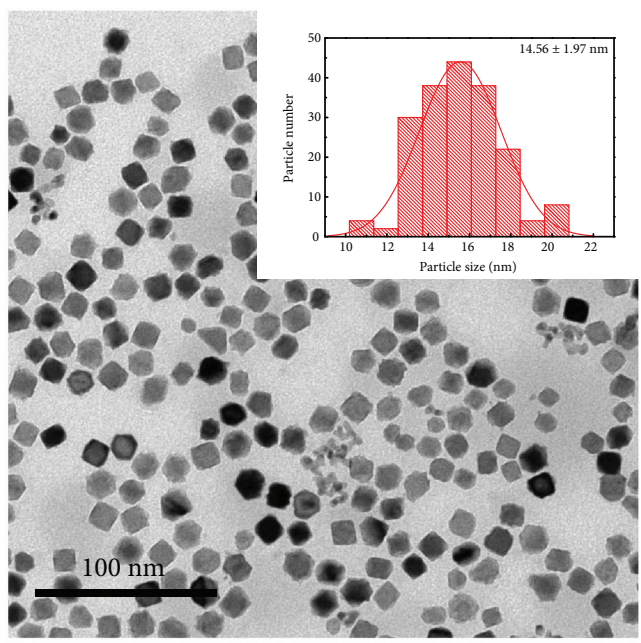

(d)

Figure 7: TEM images of the Pt nanostructures synthesized by route III with different KI concentrations: (a) 0 mmol, (b) 0.25 mmol, (c) $0.75 \mathrm{mmol}$, and (d) $1.5 \mathrm{mmol}$.

number of reduced Pt atoms may also induce to attach to the seeds, and a number of Pt seeds are formed. After that, an excess amount of $\mathrm{I}^{-}$ions was introduced in the growth solution. Due to the binding strengths of halide ions to the $\mathrm{Pt}$ surface which increase in the order of $\mathrm{Cl}^{-}, \mathrm{Br}^{-}$, and $\mathrm{I}^{-}$, Pt atoms prefer $\mathrm{I}^{-}$ions to absorb on their surface and form CTAI-encapsulated $\mathrm{Pt}^{0}$. In addition, Pt clusters can form surface-ion pairs with $\mathrm{Br}^{-}$ions, and the stabilizing electrostatic interactions cause the cationic $\mathrm{CTA}^{+}$head groups to surround the $\mathrm{Br}^{-}$layer. When the concentration of $\mathrm{I}^{-}$ions is very high, more $\mathrm{I}^{-}$ions absorb on the surface of Pt seeds and they may serve as nucleation sites to induce the aggregation of Pt NCs in the solvent. Therefore, fast anisotropic growth began and Pt nanodendrites form within a short time. Moreover, we observed that a low concentration of $\mathrm{I}^{-}$ions may not form Pt nanodendrites (Figure 5(b)).

3.3. Effect of $I$ Ions on the Growth Stage. Figure 7 shows TEM images of Pt NCs synthesized by route III with different KI concentrations, indicating that the Pt NCs are well-defined and monomorphic even at different KI concentrations. In particular, Pt dendritic structures are not formed even when the concentration of $\mathrm{I}^{-}$ions is increased to a $\mathrm{Pt}: \mathrm{I}$ ratio of $1: 30$. The increase in the KI concentration affects the particle size and shape of Pt NCs; the particles become larger and more cuboctahedral. A comparison of Figure 7(b) with Figure $7(\mathrm{~d})$ shows that cuboctahedral Pt NCs are hardly formed in the former conditions, while large amounts of cuboctahedral Pt NCs appear when the latter synthetic conditions are used. Moreover, the average size of Pt NCs obtained with extra CTAB injection does not decrease (Figure 7(a) compared to Figure 1(a)); both of them are around $11.5 \mathrm{~nm}$, but exhibit a narrow size distribution in comparison with the Pt NCs in Figure 5(a).

Figure 8 shows TEM images of Pt NCs synthesized by route IV with different KI concentrations. Route IV gives similar results to route III; again, Pt dendritic structures are not found in the products of this route, regardless of the concentration of $\mathrm{I}^{-}$ions. The increase in the concentration of $\mathrm{I}^{-}$ions does not affect the average size of $\mathrm{Pt}$ 


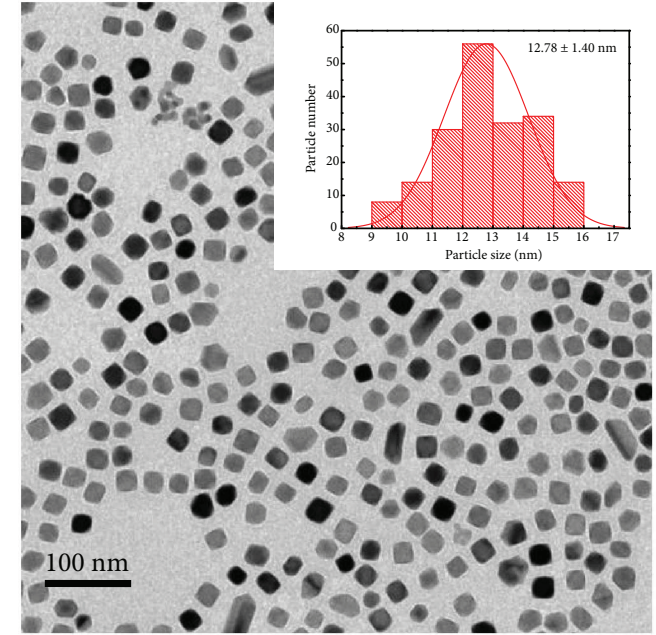

(a)

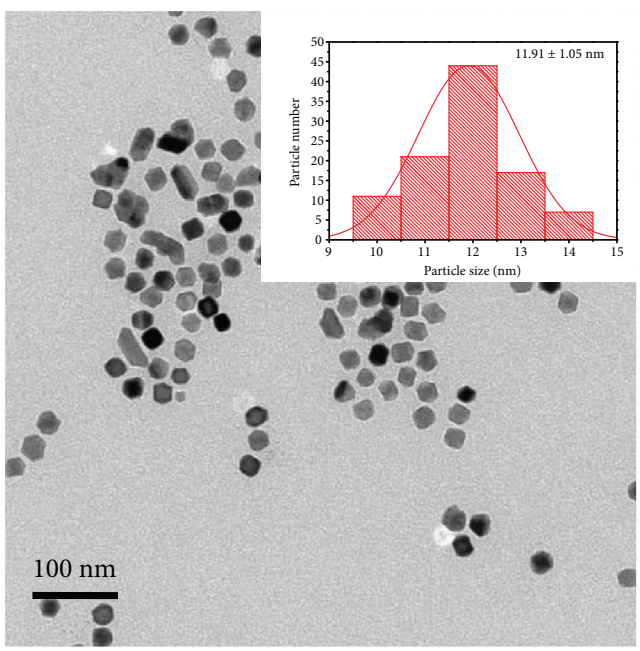

(c)

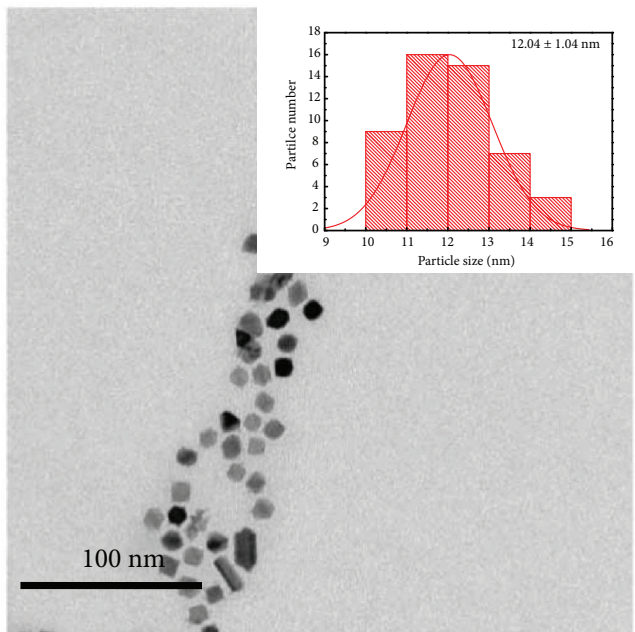

(b)

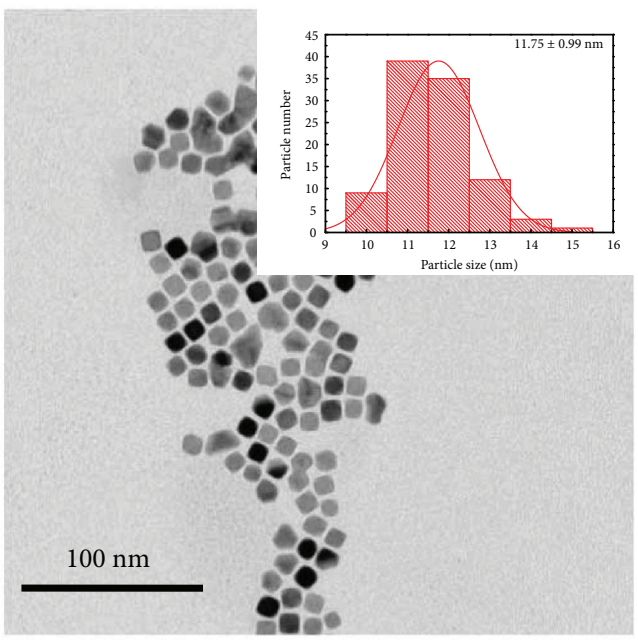

(d)

FIgure 8: TEM images of the Pt nanostructures synthesized by route IV with different KI concentrations: (a) $0 \mathrm{mM}$, (b) $0.25 \mathrm{mM}$, (c) $0.75 \mathrm{mM}$, and (d) $1.5 \mathrm{mM}$.

NCs, which is about $12 \mathrm{~nm}$. The main difference with route III is that a high concentration of $\mathrm{I}^{-}$ions does not promote the formation of cuboctahedral Pt NCs; instead, more irregular Pt NCs are generated.

The above results suggest that $\mathrm{I}^{-}$ions play different roles in different stages of $\mathrm{Pt} \mathrm{NC}$ growth. In the growth stage, high concentrations of $\mathrm{I}^{-}$ions could contribute to the shape control and generate bigger particles of Pt NCs; however, Pt seeds do not grow into dendrites. It may mean that the $\mathrm{I}^{-}$ions do not induce the aggregation of Pt NCs when the concentration of $\mathrm{Pt}^{0}$ or $\mathrm{Pt}$ seeds becomes very low in the growth solution.

\section{Conclusions}

Pt nanodendrites were successfully synthesized using the iodine ion process mediated with CTAB. The key to the synthesis of Pt nanodendrites was the addition of a large amount of $\mathrm{I}^{-}$ions to $\mathrm{K}_{2} \mathrm{PtCl}_{4}$ and the $\mathrm{CTAB}$ solution during the nucleation stage. We observed that a small portion of $\mathrm{I}^{-}$ions bound to the surfaces of Pt nanodendrites and thus may cause a rapid growth process. In addition, when the KI were added at the growth stage, the cube- and cuboctahedronshaped Pt NCs had also been obtained. This work can provide a more comprehensive understanding of the mechanism of the iodine ion synthetic process mediated by CTAB and provide a way toward a more rational design of the synthesis of morphologically controlled metal nanomaterials for their advanced functional applications.

\section{Data Availability}

The data used to support the findings of this study are available from the corresponding author upon request.

\section{Conflicts of Interest}

The authors declare that they have no conflicts of interest. 


\section{Acknowledgments}

The authors are grateful for the Project support by the ITER plan of China Ministry of Science and Technology with Grant no. 2014GB125000, International Science \& Technology Cooperation Program of China (no. 2015DFR60380), and the National Natural Science Foundation of China with Grant no. 21601170; the three funds were managed by the Institute of Nuclear Physics and Chemistry (China Academy of Engineering Physics).

\section{References}

[1] Y.-W. Lee, S. N. Cha, K.-W. Park, J. I. Sohn, and J. M. Kim, "High performance electrocatalysts based on Pt nanoarchitecture for fuel cell applications," Journal of Nanomaterials, vol. 2015, Article ID 273720, 20 pages, 2015.

[2] J. Watt, N. Young, S. Haigh, A. Kirkland, and R. D. Tilley, "Synthesis and structural characterization of branched palladium nanostructures," Advanced Materials, vol. 21, no. 22, pp. 2288-2293, 2009.

[3] A. R. Tao, S. Habas, and P. Yang, "Shape control of colloidal metal nanocrystals," Small, vol. 4, no. 3, pp. 310-325, 2008.

[4] G. Sevjidsuren, S. Zils, S. Kaserer et al., "Effect of different support morphologies and Pt particle sizes in electrocatalysts for fuel cell applications," Journal of Nanomaterials, vol. 2010, Article ID 852786, 9 pages, 2010.

[5] N. V. Long, Y. Yang, C. M. Thi, L. H. Phuc, V. P. Tuyen, and M. Nogami, "Hierarchical micro/nanoscale $\mathrm{NdFe}_{11} \mathrm{Co}$ oxide and alloy materials synthesized by polyol mediated methods with heat treatment," Materials Letters, vol. 212, no. 1, pp. 202-206, 2018.

[6] N. V. Long, M. Ohtaki, T. D. Hien, R. Jalem, and M. Nogami, "Synthesis and characterization of polyhedral and quasisphere non-polyhedral Pt nanoparticles: effects of their various surface morphologies and sizes on electrocatalytic activity for fuel cell applications," Journal of Nanoparticle Research, vol. 13, no. 10, pp. 5177-5191, 2011.

[7] W. Zhou, J. Wu, and H. Yang, "Highly uniform platinum icosahedra made by hot injection-assisted GRAILS method," Nano Letters, vol. 13, no. 6, pp. 2870-2874, 2013.

[8] G. Fu, Q. Zhang, J. Wu et al., “Arginine-mediated synthesis of cube-like platinum nanoassemblies as efficient electrocatalysts," Nano Research, vol. 8, no. 12, pp. 3963-3971, 2015.

[9] N. C. Bigall, T. Härtling, M. Klose, P. Simon, L. M. Eng, and A. Eychmüller, "Monodisperse platinum nanospheres with adjustable diameters from 10 to $100 \mathrm{~nm}$ : synthesis and distinct optical properties," Nano Letters, vol. 8, no. 12, pp. 4588-4592, 2008.

[10] M. E. Grass, R. M. Rioux, and G. A. Somorjai, "Dependence of gas-phase crotonaldehyde hydrogenation selectivity and activity on the size of Pt nanoparticles (1.7-7.1 nm) supported on SBA-15," Catalysis Letters, vol. 128, no. 1-2, pp. 1-8, 2009.

[11] K. M. Bratlie, H. Lee, K. Komvopoulos, P. Yang, and G. A. Somorjai, "Platinum nanoparticle shape effects on benzene hydrogenation selectivity," Nano Letters, vol. 7, no. 10, pp. 3097-3101, 2007.

[12] J. Chen, B. Lim, E. P. Lee, and Y. Xia, "Shape-controlled synthesis of platinum nanocrystals for catalytic and electrocatalytic applications," Nano Today, vol. 4, no. 1, pp. 81-95, 2009.
[13] C.-H. Jun, Y. J. Park, Y.-R. Yeon et al., "Demonstration of a magnetic and catalytic Co@Pt nanoparticle as a dualfunction nanoplatform," Chemical Communications, vol. 15, no. 15 , pp. 1619-1621, 2006.

[14] E. Formo, E. Lee, D. Campbell, and Y. Xia, "Functionalization of electrospun $\mathrm{TiO}_{2}$ nanofibers with $\mathrm{Pt}$ nanoparticles and nanowires for catalytic applications," Nano Letters, vol. 8, no. 2, pp. 668-672, 2008.

[15] Y. Liu, J. Chen, W. Zhang et al., "Nano-Pt modified aligned carbon nanotube arrays are efficient, robust, high surface area electrocatalysts," Chemistry of Materials, vol. 20, no. 8, pp. 2603-2605, 2008.

[16] M. Winter and R. J. Brodd, "What are batteries, fuel cells, and supercapacitors?," Chemical Reviews, vol. 104, no. 10, pp. 4245-4270, 2004.

[17] J. Greeley, I. E. L. Stephens, A. S. Bondarenko et al., "Alloys of platinum and early transition metals as oxygen reduction electrocatalysts," Nature Chemistry, vol. 1, no. 7, pp. 552-556, 2009.

[18] A. Kowal, M. Li, M. Shao et al., "Ternary $\mathrm{Pt} / \mathrm{Rh} / \mathrm{SnO}_{2}$ electrocatalysts for oxidizing ethanol to $\mathrm{CO}_{2}$," Nature Materials, vol. 8, no. 4, pp. 325-330, 2009.

[19] M. Chen, B. Wu, J. Yang, and N. Zheng, "Small adsorbateassisted shape control of Pd and Pt nanocrystals," Advanced Materials, vol. 24, no. 7, pp. 862-879, 2012.

[20] T. K. Sau and A. L. Rogach, "Nonspherical noble metal nanoparticles: colloid-chemical synthesis and morphology control," Advanced Materials, vol. 22, no. 16, pp. 1781-1804, 2010.

[21] T. S. Ahmadi, Z. L. Wang, A. Henglein, and M. A. el-Sayed, "“Cubic" colloidal platinum nanoparticles," Chemistry of Materials, vol. 8, no. 6, pp. 1161-1163, 1996.

[22] Z. L. Wang, "Transmission electron microscopy of shapecontrolled nanocrystals and their assemblies," The Journal of Physical Chemistry B, vol. 104, no. 6, pp. 1153-1175, 2000.

[23] H. Song, F. Kim, S. Connor, G. A. Somorjai, and P. Yang, "Pt nanocrystals: shape control and Langmuir-Blodgett monolayer formation," The Journal of Physical Chemistry B, vol. 109, no. 1, pp. 188-193, 2005.

[24] E. P. Lee, Z. Peng, D. M. Cate, H. Yang, C. T. Campbell, and Y. Xia, "Growing Pt nanowires as a densely packed array on metal gauze," Journal of the American Chemical Society, vol. 129, no. 35, pp. 10634-10635, 2007.

[25] J. Yin, J. Wang, M. Li, C. Jin, and T. Zhang, "Iodine ions mediated formation of monomorphic single-crystalline platinum nanoflowers," Chemistry of Materials, vol. 24, no. 14, pp. 2645-2654, 2012.

[26] C. E. Hoppe, M. Lazzari, I. Pardiñas-Blanco, and M. A. LópezQuintela, "One-step synthesis of gold and silver hydrosols using poly( $N$-vinyl-2-pyrrolidone) as a reducing agent," Langmuir, vol. 22, no. 16, pp. 7027-7034, 2006.

[27] Y. Borodko, S. E. Habas, M. Koebel, P. Yang, H. Frei, and G. A. Somorjai, "Probing the interaction of poly(vinylpyrrolidone) with platinum nanocrystals by UV-Raman and FTIR," The Journal of Physical Chemistry B, vol. 110, no. 46, pp. 2305223059, 2006.

[28] H. Lee, S. E. Habas, S. Kweskin, D. Butcher, G. A. Somorjai, and P. Yang, "Morphological control of catalytically active platinum nanocrystals," Angewandte Chemie International Edition, vol. 45, no. 46, pp. 7824-7828, 2006.

[29] M. H. Ullah, W.-S. Chung, I. Kim, and C.-S. Ha, "pH-selective synthesis of monodisperse nanoparticles and $3 \mathrm{D}$ dendritic 
nanoclusters of CTAB-stabilized platinum for electrocatalytic $\mathrm{O}_{2}$ reduction," Small, vol. 2, no. 7, pp. 870-873, 2006.

[30] J. Chen, T. Herricks, M. Geissler, and Y. Xia, "Single-crystal nanowires of platinum can be synthesized by controlling the reaction rate of a polyol process," Journal of the American Chemical Society, vol. 126, no. 35, pp. 10854-10855, 2004.

[31] J. Chen, T. Herricks, and Y. Xia, "Polyol synthesis of platinum nanostructures: control of morphology through the manipulation of reduction kinetics," Angewandte Chemie, vol. 44, no. 17, pp. 2589-2592, 2005.

[32] T. Herricks, J. Chen, and Y. Xia, "Polyol synthesis of platinum nanoparticles: control of morphology with sodium nitrate," Nano Letters, vol. 4, no. 12, pp. 2367-2371, 2004.

[33] T. Yu, D. Y. Kim, H. Zhang, and Y. Xia, "Platinum concave nanocubes with high-index facets and their enhanced activity for oxygen reduction reaction," Angewandte Chemie, vol. 50, no. 12, pp. 2773-2777, 2011.

[34] M. Miyake and K. Miyabayashi, "Shape and size controlled Pt nanocrystals as novel model catalysts," Catalysis Surveys from Asia, vol. 16, no. 1, pp. 1-13, 2012.

[35] M. Ma, Y. Zhang, and N. Gu, "Peroxidase-like catalytic activity of cubic Pt nanocrystals," Colloids and Surfaces A: Physicochemical and Engineering Aspects, vol. 373, no. 1-3, pp. 6-10, 2011.

[36] S. M. Humphrey, M. E. Grass, S. E. Habas, K. Niesz, G. A. Somorjai, and T. D. Tilley, "Rhodium nanoparticles from cluster seeds: control of size and shape by precursor addition rate," Nano Letters, vol. 7, no. 3, pp. 785-790, 2007.

[37] J. M. Petroski, Z. L. Wang, T. C. Green, and M. A. el-Sayed, "Kinetically controlled growth and shape formation mechanism of platinum nanoparticles," The Journal of Physical Chemistry B, vol. 102, no. 18, pp. 3316-3320, 1998.

[38] K. A. Razak, S. H. Neoh, N. S. Ridhuan, and N. M. Nor, "Effect of platinum-nanodendrite modification on the glucosesensing properties of a zinc-oxide-nanorod electrode," Applied Surface Science, vol. 380, pp. 32-39, 2016.

[39] Z. Cheng, X. Chu, J. Xu, H. Zhong, and L. Zhang, "Synthesis of flower-like and dendritic platinum nanostructures with excellent catalytic activities on thermal decomposition of ammonium perchlorate," Materials Research Bulletin, vol. 77, pp. 54-59, 2016.

[40] M. Nogami, R. Koike, R. Jalem, G. Kawamura, Y. Yang, and Y. Sasaki, "Synthesis of porous single-crystalline platinum nanocubes composed of nanoparticles," Journal of Physical Chemistry Letters, vol. 1, no. 2, pp. 568-571, 2010.

[41] F. Wang, C. Li, L. D. Sun et al., "Porous single-crystalline palladium nanoparticles with high catalytic activities," Angewandte Chemie International Edition, vol. 51, no. 20, pp. 4872-4876, 2012. 


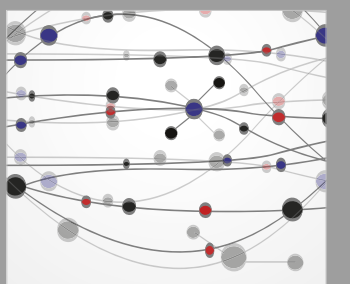

The Scientific World Journal
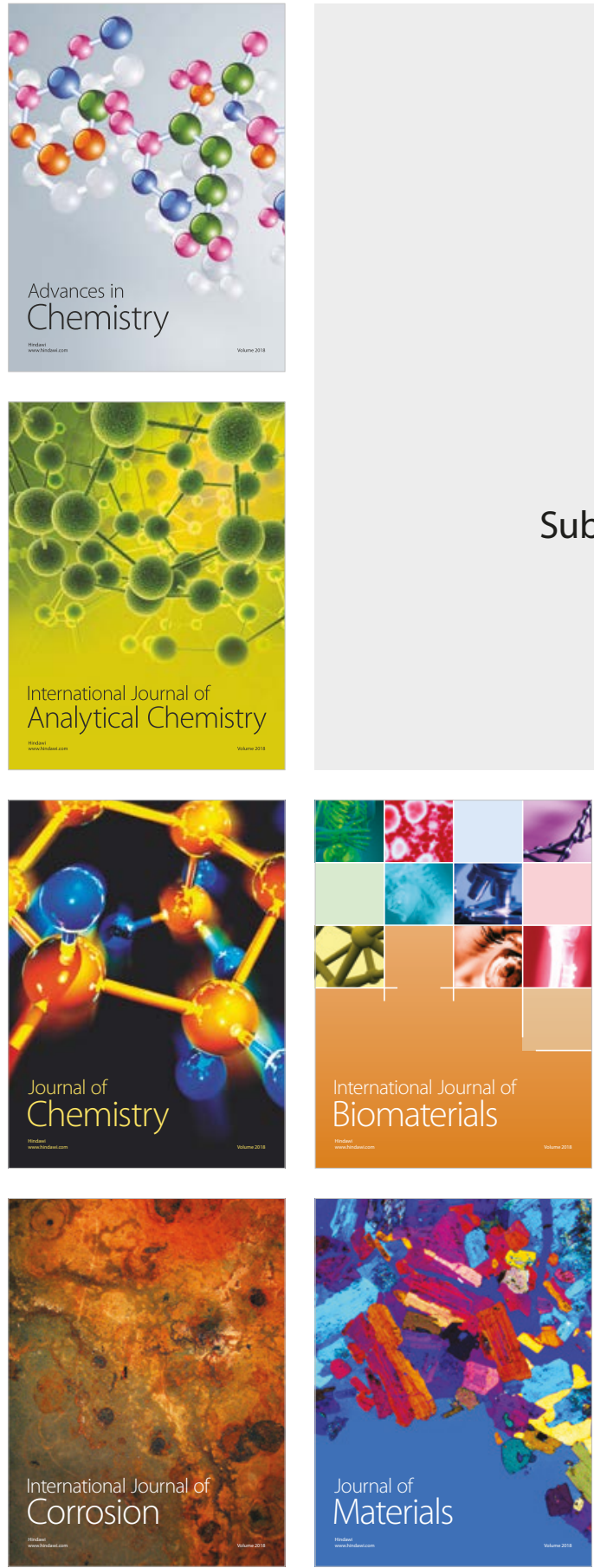

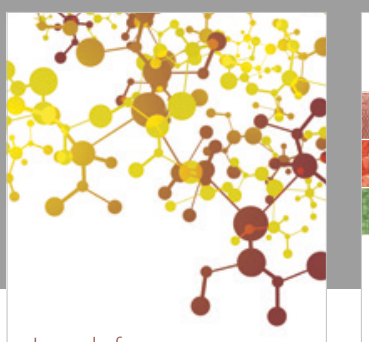

Journal of

Applied Chemistry
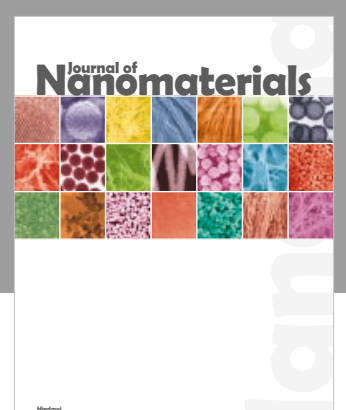

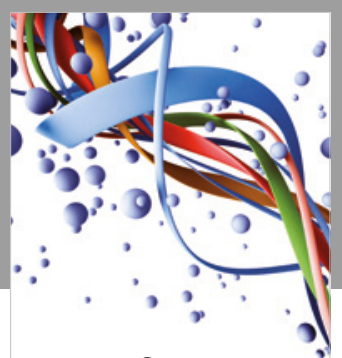

Scientifica

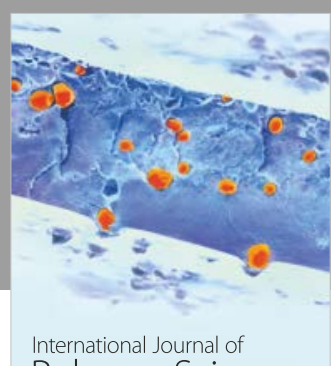

Polymer Science

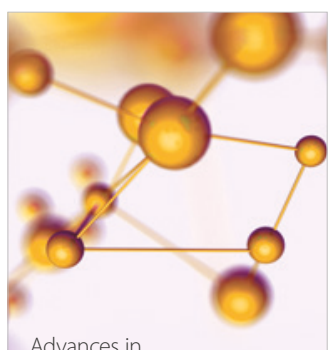

Physical Chemistry
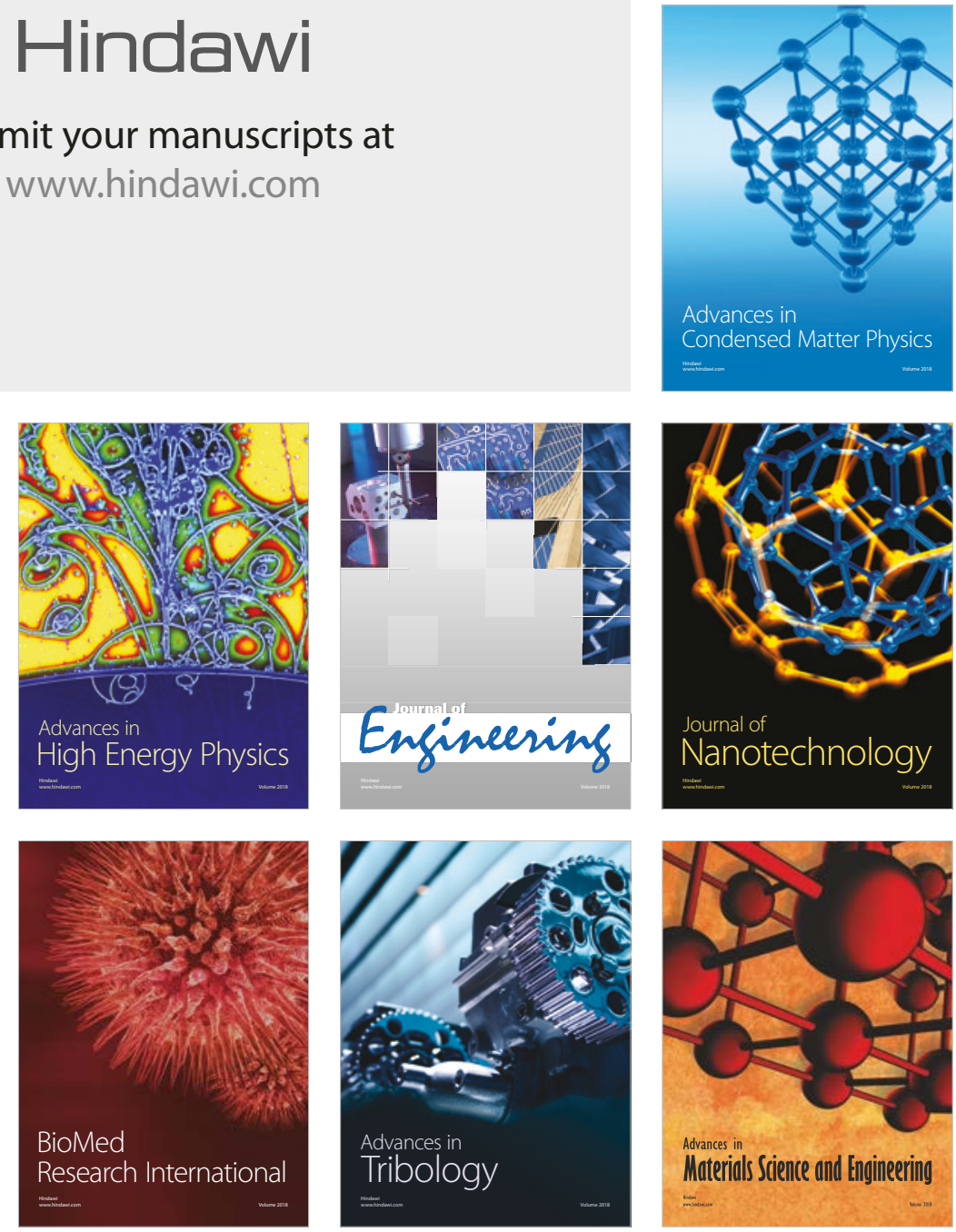